\title{
Elution of ${ }^{111}$ Indium from reticuloendothelial cells
}

\author{
AM PETERS, I KLONIZAKIS, JP LAVENDER, SM LEWIS \\ From the Department of Diagnostic Radiology, Hammersmith Hospital, Du Cane Road, London W12
}

SUMMARY Measurement of isotope accumulation in an organ is often used to assess that organ's removal of blood cells labelled with the isotope. This technique is only valid if the isotope does not elute from the organ. Elution of ${ }^{111}$ In from the liver and spleen has been investigated in 14 subjects following intravenous injection of heat-damaged erythrocytes labelled with ${ }^{111} \mathrm{In}$. The elution rate from the spleen was found to be low, about $2 \%$ of the initial activity per day. The liver accumulated activity with respect to its initial uptake at a rate of about $5 \%$ per day. Bone marrow was not visualised except in two patients in whom it was identifiable in the initial scan.

The accumulation of isotope within an organ is often used as a measurement of uptake by that organ of blood cells previously labelled with the isotope. Examples of this are the accumulation of ${ }^{51} \mathrm{Cr}$ in the spleen and liver, detected by surface counting, after injection of ${ }^{51} \mathrm{Cr}$-labelled erythrocytes, and the accumulation of ${ }^{111} \mathrm{In}$ in the same organs, following injection of ${ }^{111}$ In-labelled platelets. The validity of this approach depends on the organ retaining the radioactivity after uptake of the cells. Thus, our conclusion in earlier papers ${ }^{12}$ that the main organs responsible for removing effete ${ }^{111}$ In-labelled platelets from the circulation are the spleen and the bone marrow rested on the assumption that ${ }^{111}$ In taken up in these organs did not re-enter the circulation and become redistributed to other parts of the reticuloendothelial system. The elution of ${ }^{51} \mathrm{Cr}$ from the spleen has been found to be about $6 \%$ per day. ${ }^{3}$ If the corresponding figure for ${ }^{111} \mathrm{In}$ was similar to this, then our assumption would not be justified. We undertook, therefore, a study to assess the elution rate of ${ }^{111}$ In from the liver and spleen.

\section{Material and methods}

Eleven patients undergoing heat-damaged red cell clearance studies for assessment of activity of their rheumatic disorders ${ }^{4}$ and three normal volunteers were used in this study. Two $\mathrm{ml}$ of washed erythrocytes were separated from heparinised whole blood and heated in a glass container at $49 \cdot 5^{\circ} \mathrm{C}$ for $20 \mathrm{~min}$. After washing, they were labelled with ${ }^{111}$ In-oxine ${ }^{5}$ or ${ }^{111}$ In acetylacetone. ${ }^{6}$ Labelling efficiency was consistently greater than $90 \%$. After reinjection, blood samples were taken at intervals for up to 60

Accepted for publication 30 September 1981 min for the calculation of clearance rate. After $24 \mathrm{~h}$, gamma camera scanning of the chest and upper abdomen was performed and a blood sample taken. Scanning was repeated under identical conditions on at least one occasion between three and eight days after the first scan. The computer images were analysed for the total counts collected per unit time in regions over the spleen, liver and lumbar spine. The regions were recorded so that they could be recalled when the same patient was rescanned. The total counts in a region were corrected for background and isotope decay and expressed as a percentage of the $24 \mathrm{~h}$ (initial) value.

\section{Results}

All the patients studied had normal clearance values ${ }^{7}$ and normal-sized spleens. The circulating ${ }^{111}$ In concentration was very low (less than $1 \%$ of the dose) at $24 \mathrm{~h}$, and remained so throughout. It was essentially non-cell bound. Most of the administered activity localised in the spleen, with much less going to the liver (Fig. 1). The decay corrected activity levels in the spleen and liver, expressed as a percentage of the $24 \mathrm{~h}$ level, are shown in Fig. 2 . Regression analysis gave a rate of loss of activity from the spleen of $2.0 \%$ of the $24 \mathrm{~h}$ activity per day with a $95 \%$ confidence interval of $-4 \cdot 2 \%$ to $0 \cdot 16 \%$ per day, and a rate of accumulation in the liver of $5.4 \%$ of $24 \mathrm{~h}$ activity per day with $95 \%$ confidence limits of $11.0 \%$ and $-0.5 \%$ per day. Only two patients displayed bone marrow signals at any stage large enough to observe changes; in these, the marrow to spleen ratios appeared to fall slightly. These two patients also showed high liver uptakes. During the course of the clearance study itself, much activity was visible in the lung fields. However, 


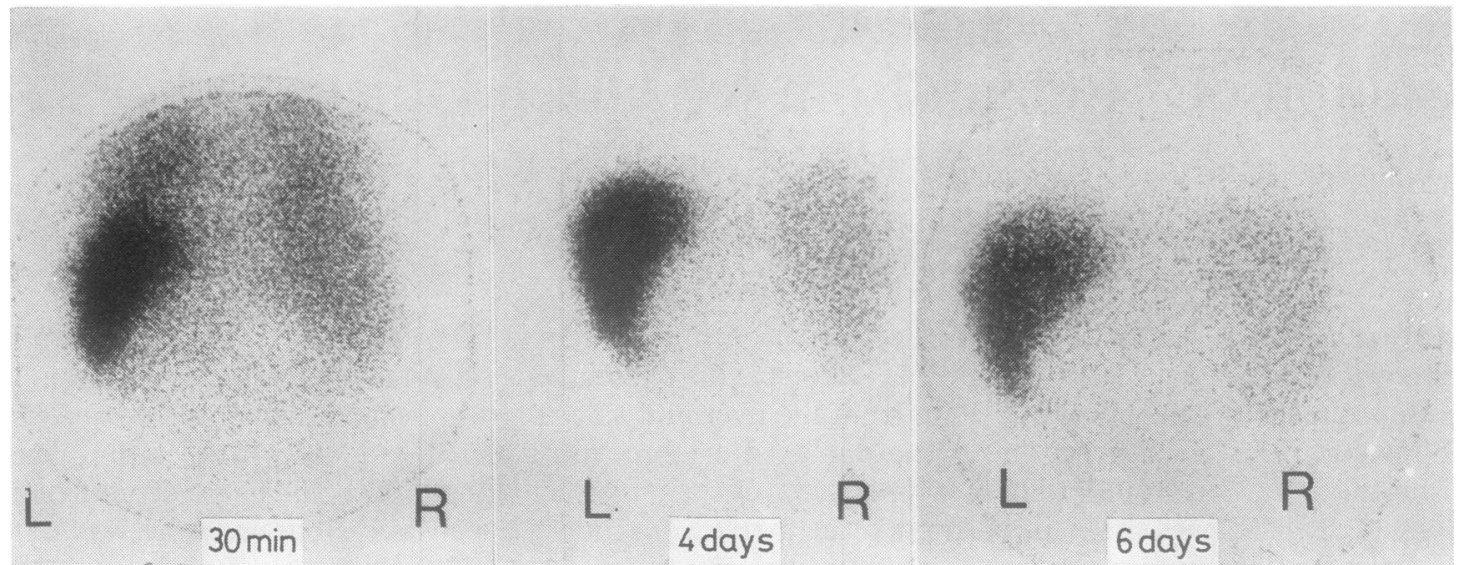

Fig. 1 Posterior gamma camera scans taken at 30 min, 4 and 6 days after injection of ${ }^{111}$ In labelled heat-damaged erythrocytes. At $30 \mathrm{~min}$, activity is present in lung fields, liver $(R)$ and spleen $(L)$, but none in bone marrow. In later scans, spleen and liver activity persists whereas the lung fields become clear. Bone marrow remains invisible.

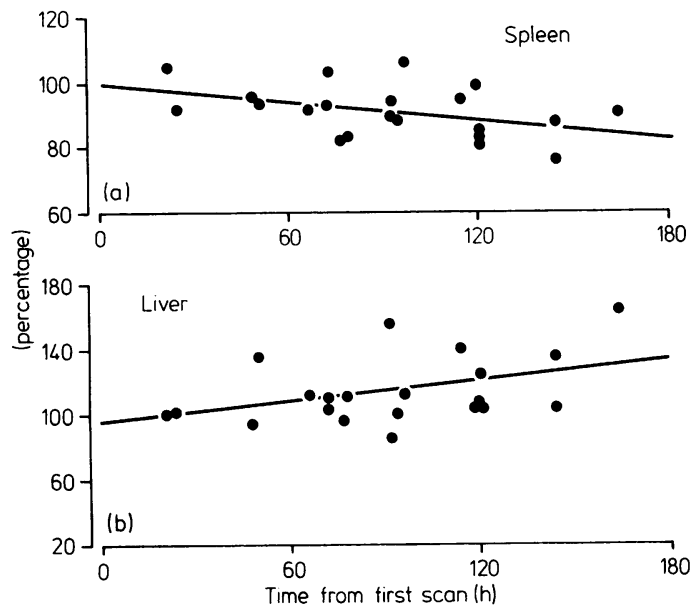

Fig. 2 Changes in (a) splenic and (b) hepatic ${ }^{111}$ In, after injection of heat-damaged erythrocytes labelled with ${ }^{111}$ In. Decay corrected count rates are expressed as the percentage of the value at $24 \mathrm{~h}$. The continuous line is the line of regression. (Pooled data from 14 patients.)

at $24 \mathrm{~h}$, lung activity had entirely disappeared (Fig. 1).

\section{Discussion}

We conclude from this study that red cell-bound 111In taken up by the spleen shows a slow rate of elution over a period of eight days. Because ${ }^{111}$ In losses via urine and faeces are very low $^{8}$ and because injected free ${ }^{111}$ In localises selectively in spleen, bone marrow and particularly liver, ${ }^{9}$ redistribution would have been expected to produce a bone marrow image, a falling spleen count and a rising liver count. Such redistribution occurred slowly. Although bone marrow was clearly visualised in two patients, the decay corrected counts did not change appreciably with time, nor did their ratio with the spleen counts. The effect of lung uptake on ${ }^{111}$ In redistribution need only be considered over the first $24 \mathrm{~h}$, since after this time lung activity had disappeared and did not reaccumulate. This study, therefore, supports the claim that increasing marrow radioactivity after injection of ${ }^{111}$ In labelled platelets does indeed reflect uptake by the marrow of effete platelets. The stability of intracellular ${ }^{111}$ In should make this a useful isotope for other, similar, haematological investigations, such as the quantification of red cell destruction in severe haemolytic anaemias in which red cell life span is compatible with the half life of ${ }^{111} \mathrm{In}$. An interpretation of bone marrow uptake of heat-damaged red cells, when it occurs, cannot be made from this limited data, but because of its possible association with heavy liver uptake, may be a reflection of excessive damage.

The authors wish to thank M Deenmamode, Ann Biggins and Rina Van der Spuy. AMP is supported by the Cancer Research Campaign. The support of the MRC is acknowledged.

\section{References}

${ }^{1}$ Klonizakis I, Peters AM, Fitzpatrick ML, Kensett MJ, Lewis SM, Lavender JP. Radionuclide distribution following injection of ${ }^{111}$ Indium labelled platelets. $\mathrm{Br} J$ Haematol 1980;46:595-602.

${ }^{2}$ Klonizakis I, Peters AM, Fitzpatrick ML, Kensett MJ, Lewis SM, Lavender JP. Spleen function and platelet 
kinetics. J Clin Pathol 1981 ;34:377-80.

${ }^{3}$ Williams ED, Ahuja S, Szur L, Lewis SM, Glass HI. Rate of loss of ${ }^{51} \mathrm{Cr}$ from the spleen. Br J Radiol 1972;48: 275-8.

- Elkon KB, Sewell JR, Ryan PFJ, Hughes GRV. Splenic function in non-renal systemic lupus erythematosus. $\mathrm{Am}$ J Med 1980;69:80-2.

${ }^{5}$ Thakur ML, Coleman RE, Welch MJ. Indium-111 labelled leukocytes for the localisation of abscesses: preparation, analysis, tissue distribution and comparison with gallium-67 citrate in dogs. J Lab Clin Med 1977; 89:217-28.

${ }^{6}$ Sinn H, Silvester DJ. Simplified cell labelling with indium111-acetylacetone. Br J Radiol 1979;52:758-9.
7 Petitt JE. Spleen function. Clin Haematol 1977;6:639-56.

${ }^{8}$ Goodwin DA, Bushberg JT, Doherty PW, et al. Indium111 labelled autologous platelets for location of vascular thrombi in humans. $J$ Nucl Med 1978;19:626-34.

${ }^{9}$ Merrick MV, Gordon-Smith EC, Lavender JP, Szur L. Comparison of ${ }^{111}$ Indium with ${ }^{52} \mathrm{Fe}$ and ${ }^{99} \mathrm{~m} \mathrm{Tc}$ sulphur colloid for bone marrow scanning. J Nucl Med 1975; 16:66-8.

Requests for reprints to: Dr AM Peters, Diagnostic Radiology Department, Hammersmith Hospital, Du Cane Road, London W12, England. 